\title{
Water Vapor in Closed-Cell In Situ Gas Reactions: Initial Experiments
}

\author{
Kinga A. Unocic ${ }^{1}$, Abhaya K. Datye ${ }^{2}$, Wilbur C. Bigelow ${ }^{3}$ and Lawrence F. Allard ${ }^{1}$ \\ ${ }^{1 .}$ Materials Science and Technology Division, Oak Ridge National Laboratory, Oak Ridge, TN, USA. \\ 2. Chemical \& Biological Engineering, University of New Mexico, Albuquerque, NM, USA. \\ 3. Department of Materials Science \& Engineering, University of Michigan, Ann Arbor, MI, USA.
}

Modern technology for in situ closed-cell gas-flow allows reactions to be conducted at elevated temperatures and at gas pressures up to one atmosphere [1]. However, introducing water vapor into the cell at percentages above the $\sim 2 \%$ possible with room-temperature air at $100 \%$ relative humidity (e.g. to mimic bench-top reaction conditions) remains challenging due to the impracticality of heating the gas feed lines into the cell that is necessary to prevent water condensation. Water-vapor experiments are being performed using as a trial specimen $\mathrm{MgO}$ nanoparticles (from burning $\mathrm{MgO}$ ribbon and collecting the smoke). $\mathrm{MgO}$ is a hygroscopic mineral that converts to $\mathrm{Mg}(\mathrm{OH})_{2}$ (brucite) when exposed to water. Because the $\mathrm{MgO}$ smoke nanoparticles form perfect cubes, it was hypothesized that they could serve as a sensitive indicator for the presence of water vapor in the closed-cell gas-reactor holder. In situ results will ultimately be correlated to similar experiments performed in an ex situ reactor to confirm the presence of $\mathrm{H}_{2} \mathrm{O}$ vapor in the cell. Results of preliminary experiments are described here.

$\mathrm{MgO}$ smoke particles were collected on a Protochips E-chip heater, where the chip was masked to isolate the heater membrane such that $\mathrm{MgO}$ particles deposited only on the heater surface. Figure 1 shows typical $\mathrm{MgO}$ cubes deposited on the thin $(30 \mathrm{~nm})$ silicon nitride membrane. Temperature effects on the stability of the $\mathrm{MgO}$ crystals were initially investigated by heating the E-chip with $\mathrm{MgO}$ deposited on it in the column vacuum to $1000^{\circ} \mathrm{C}$ at $5^{\circ} \mathrm{C} / \mathrm{s}$. The $\mathrm{MgO}$ crystals were extremely stable under vacuum heating; coarsening of the crystals initiated only at $950^{\circ} \mathrm{C}$. The $\mathrm{MgO}$ crystals were then heated in lab air at $\sim 50 \% \mathrm{RH}$ (i.e. $\sim 1 \% \mathrm{H}_{2} \mathrm{O}$ vapor at atmospheric presssure); there was no discernible difference between heating in vacuum and in lab air. The crystals in lab air were stable up to $950^{\circ} \mathrm{C}$.

For the ex situ experiments, a special-built reactor fitted with a port to hold the JEOL specimen rod was used, and was wrapped with heating tape to prevent water condensation. Water was injected (with dry air as a carrier gas) into the chamber at $9 \mathrm{ml} / \mathrm{hr}$, which allowed $48 \%$ water vapor with a gas flow of 500 $\mathrm{mL} / \mathrm{min}$, while introduction of $10 \%$ of water vapor required $200 \mathrm{~mL} / \mathrm{min}$ gas flow. The internal temperature was monitored by a thermocouple placed in the center of the reaction chamber; calculations indicated that heating to $85^{\circ} \mathrm{C}$ would preclude moisture condesation on the chamber wall and the holder.

In the first experiment, a $48 \% \mathrm{H}_{2} \mathrm{O}$ vapor condition was attempted, but it was noted that water droplets did in fact condense on the walls of the ex situ reaction chamber and the heater holder tip (likely due to insufficient time for equilibrium temperature to be reached before injecting the vapor). Therefore, $\mathrm{MgO}$ crystals were exposed to both water vapor and water for $\sim 1 \mathrm{~min}$. without applying E-chip heating. This was fortuitous, because examination of the $\mathrm{MgO}$ crystals clearly showed formation of the brucite outer oxide layer having an irregular, spiky-type morphology and a thickness of $\sim 5 \mathrm{~nm}$ (Figure 2). The question to ask was if the spiky-type oxide layer would also form with only water vapor present, which was explored by exposing a new chip with $\mathrm{MgO}$ smoke cubes to flowing lab air with $10 \% \mathrm{H}_{2} \mathrm{O}$ vapor at $700^{\circ} \mathrm{C}$ for $30 \mathrm{~min}$. in a separate bench-top furnace system. As shown in Figure 3, the $\mathrm{MgO}$ cubes showed that a thin amorphous layer was formed, and that the sharp cube corners became more rounded. No increased sintering of $\mathrm{MgO}$ crystals was observed; however, it was subsequently noted that brucite 
dissociates at elevated temperatures, and a new experiment at e.g. $200^{\circ} \mathrm{C}$ would be a better test. This experiment, and others planned, are required to better determine whether $\mathrm{MgO}$ crystals can be a good indicator for in situ closed-cell gas-reaction with water vapor experiments, or if an alternative material should be used [4].

\section{References:}

[1] L F Allard, et al., Microsc. Microanal. 18 (2012), p. 656.

[2] P J Anderson and P L Morgan, Trans. Faraday Soc. 60 (1964), p. 930.

[3] K A Unocic et al., Oxid. Metals on line (2017) p.1.

[4] Research sponsored by the Laboratory Directed Research and Development Program of Oak Ridge National Laboratory, managed by UT-Battelle, LLC, for the U. S. Department of Energy.
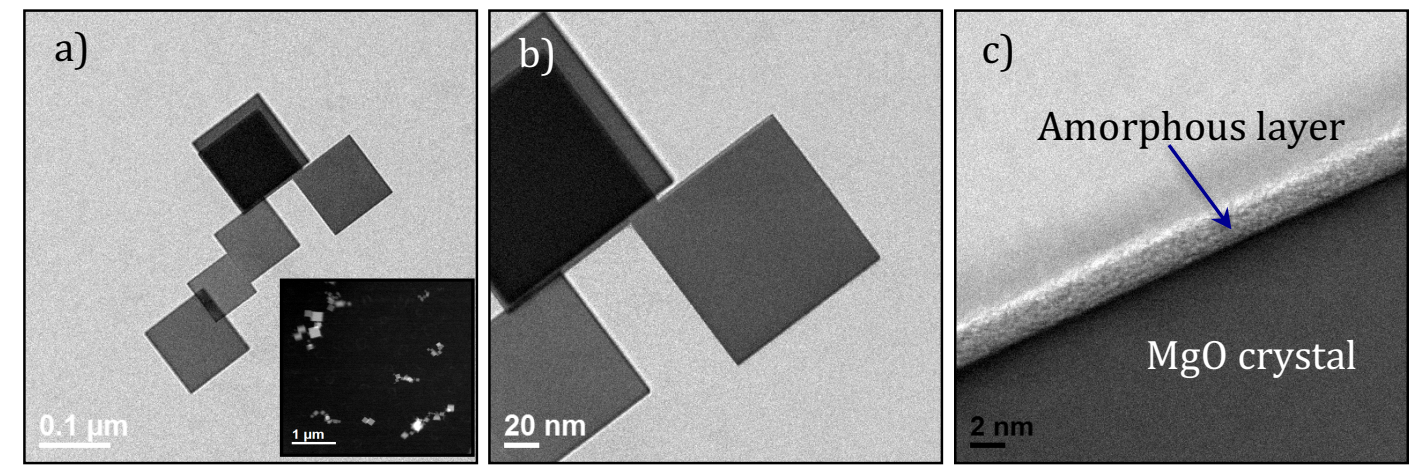

Figure 1. BF-STEM images of $\mathrm{MgO}$ crystals, after smoke deposition on electron transparent $\mathrm{SiN}$ region of Protochips E-chip. Crytals are perfectly faceted with cube morphology, and have sharp corners.
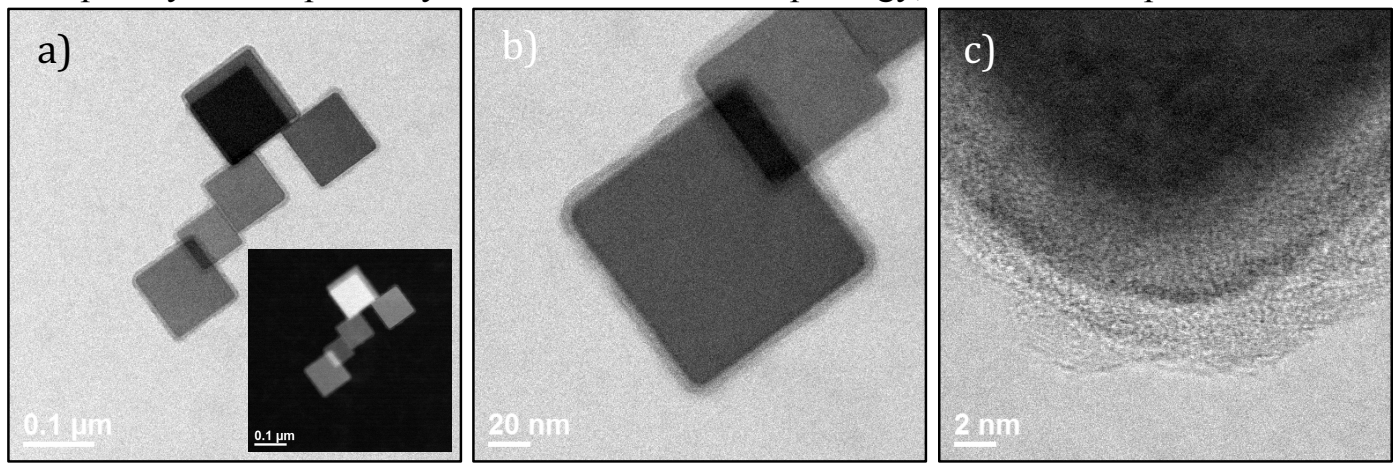

Figure 2. BF-STEM images of $\mathrm{MgO}$ crystals, area of Fig. 1, after ex situ water and water vapor 1 minute exposure at $85^{\circ} \mathrm{C}$. Sharp corners became rounded, and the surface converted to a 5-6nm spikey film.
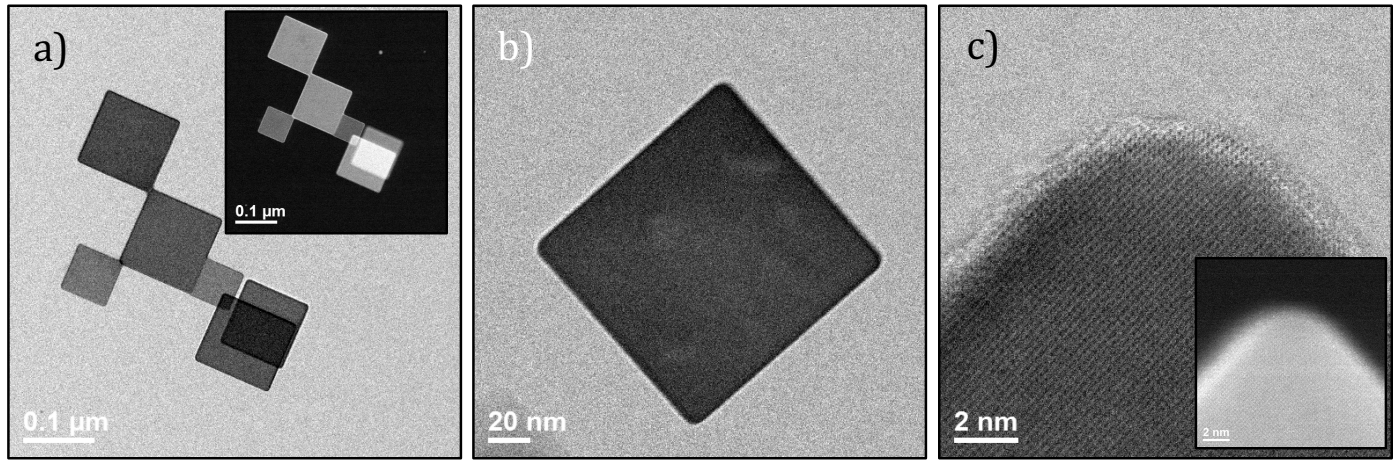

Figure 3. BF-STEM images of $\mathrm{MgO}$ crystals, after lab ex situ exposure $\left(700^{\circ} \mathrm{C} / 0.5 \mathrm{~h} \mathrm{lab} \mathrm{Air}+10 \% \mathrm{H}_{2} \mathrm{O}\right)$ on electron transparent $\mathrm{SiN}$. Crystals remained perfectly faceted, but. the corners of the $\mathrm{MgO}$ crystals became rounded instead of sharp. 